\title{
Recovering Subsidized Housing Developments in Northern México: The Critical Role of Public Space in Community Building in the Context of a Crime and Violence Crisis
}

\author{
Gabriel Díaz Montemayor \\ Fay Jones School of Architecture and Design, University of Arkansas, Fayetteville, AR 72701, USA; \\ gabogaz@gmail.com
}

Received: 7 August 2019; Accepted: 27 September 2019; Published: 2 October 2019

\begin{abstract}
México has subsidized and built millions of low-income homes and thousands of subdivisions in the period of 2000-2012. These occupied and expanded urban peripheries far away from work, learn, service, commerce, and recreational amenity centers. These communities had no chance to offer a high quality of life. They were rapidly abandoned and deteriorated physically and socially. Amid the still ongoing crime and violence, inhabitants experienced a loss of trust in their neighbors, a deep sense of insecurity, and consequently reduced public life and activity to a minimum. This article describes and reflects on a project implemented in two neighborhoods of two northern México cities, with the objective of mitigating crime and violence, while recovering public spaces in these communities. The project implemented a hybridized methodology, including Crime Prevention Through Environmental Design (CPTED), attention to Youth at Risk, and the prevention of Gender Based Violence. All these were integrated transversally with a community participation approach incorporated throughout the project actions. This article reflects on the successes and failures of this pilot project, as demonstrated by differentiated results between a neighborhood located in Chihuahua City and another in the municipality of Guadalupe, within Monterrey's Metro Area. The lessons learned, include the relevance of local political timing and interests, the importance of accurate and manageable geographic definitions for the areas of implementation, the role of NGOs, the importance of local educational institutions-in particular schools of architecture and the need for community oriented strategic consultants, to appropriately advise local governments in the implementation of projects of this nature. The article demonstrates the effort to make it accessible, and to anticipate the issues and opportunities as many Mexican, and other Latin American countries and cities engage in the spatial and social recovery of public spaces, neighborhoods, communities, and cities after years of high crime and violence.
\end{abstract}

Keywords: CPTED; youth at risk; public space recovery; prevention of gender-based violence; tactical urbanism

\section{Introduction}

This article describes and critically reflects on a pilot project intended to socially and physically recover public spaces. The project's objective was to mitigate crime and violence through a series of spatial/urban and social interventions implemented in two urban areas of northern México cities during the years of 2017 to 2018. The project leverages a growing momentum and awareness of social and spatial intervention tools, such as Tactical Urbanism, a practice that is growing in Latin America [1]. This project explored the potential to hybridize and create a methodology that incorporates three main concepts and their associated established methods. The three main concepts or methods were: 
Crime Prevention Through Environmental Design (CPTED); attention to Youth at Risk (AYAR); and the Prevention of Gender Based Violence (PGBV).

Being a pilot-test-project, the basic practical question was, "whether there could be a way to effectively integrate CPTED, AYAR, and PGBV, in a model that could be replicated in other urban neighborhoods or districts of México and Latin America". The premise was a challenge, as these three areas have their own processes, methods, and tools, and are not necessarily easily arranged in an operational critical route for implementation, especially when multiple actors are involved.

The two selected neighborhoods are in the City of Chihuahua, in the Municipality and State of Chihuahua, and in the Municipality of Guadalupe, part of the Metropolitan Area of Monterrey, in the State of Nuevo León, México. Chihuahua's selected neighborhood was Riberas del Sacramento-Spanish for Sacramento Riverside, henceforth the 'Chihuahua neighborhood'. Guadalupe's selected neighborhood was Paseo Guadalupe-Spanish for Guadalupe Promenade, henceforth 'Guadalupe neighborhood' (see Figure 1). Both neighborhoods are composed of recently developed subsidized low-income housing subdivisions.

During the first 12 years of the current century, the country of México implemented an aggressive program [2] of subsidized housing construction as the federal government, shifted from acting as a developer and builder to a financier of a housing production. Unfortunately, a vast number of these subdivisions were inadequately located in their towns and cities [3]. Many were positioned in large, wide, empty, and expansive urban peripheries, including the Chihuahua neighborhood, and many others situated mostly in the vacant urban fringes of expansive metropolitan areas. The case of the Guadalupe neighborhood is similar, however, this community is surrounded by other low-income subdivisions and vacant properties, while the Chihuahua neighborhood is like an island, surrounded by vacant and agricultural lands, detached from the city's urban fabric and infrastructure [4], except for a highway connecting it to the city.

In 2006, the Mexican Federal Government declared the "War on Drugs" by a massive militarization and intensification of policing activities in the country [5]. The unintended consequences of this action, included the expansion of criminal activities beyond the conventional drug trade, including kidnappings and extortion, which made the peri-urban areas an easy prey for territorializing by organized crime, as cartels were beheaded and transformed. Gangsters increased their recruitment of youth in many of the new subdivisions and made these areas a significant location for their criminal activities. Along with long commuting distances to work, service, commerce and education centers, inadequate architectural quality of housing, inability to pay credits, this made the subdivisions undesirable and/or unaffordable places to live for many. A high national perception of insecurity has also contributed to the abandonment of housing and public spaces, taking public life out of street life, parks, and plazas, which are included in the master planned subsidized communities. Both Chihuahua and Monterrey Metro are also among the Mexican cities with highest murder rates-above 65.3 homicides per 100,000 [6].

Another critical problem in México is gender-based violence. Verbal and physical aggression inflicted by male romantic partners to their female partners is a mute, as it is often not denounced [7]. This type of violence is very common and normalized in México. The 2016 National Survey on Home Relationships Dynamics (ENDIREH) delivered dismal indicators on this for women over 15 years of age in México: Where 29\% have suffered economic violence or work discrimination, $34 \%$ have suffered physical violence, $49 \%$ have endured emotional violence, and $41.3 \%$ have suffered sexual violence [8].

Both the Chihuahua and the Guadalupe neighborhoods were selected by their municipal governments as neighborhoods suitable for assessing the implementation of the CPTED-AYAR-PGBV project. The selection occurred through the analysis of municipal authorities of crime and violence statistics, controlled by municipal police departments.

The implementation of this pilot project was supported by technical support, provided by the United States Agency for International Development (USAID), through its contractor Chemonics International, to local municipal governments who have agreed to provide their institutional resources. 
This was executed within an umbrella program called "Juntos por la prevención de la violencia", Spanish for "Together for the Prevention of Violence." The author of this article was the general consultant, leading the technical team supporting local governments. In each city, there was a local expert hired to implement the CPTED strategies, as well as community participation methods and techniques. The international development agency supervised the technical team, facilitated and coordinated with the municipal government entities, including an active participation of the mayors.

\section{Materials and Methods}

The hybridization of the three methodologies was, since the beginning, understood as a pilot project to be evaluated through its implementation. Evidence based results were expected. Therefore, one of the intended first steps was the planning and collection of baseline data against which to compare results as the project strategies and tactics were implemented. The project was envisioned by the technical team and the partnering local governments as a social and environmental intervention. As such, it was meant to demonstrate a social impact by diminishing indicators of crime and violence. Also, integral to the project was the materialization of an environmental, physical, and spatial impact, as demonstrated by reclaimed public spaces, active streets, parks, and plazas.

\subsection{CPTED}

The unifying methodology, among the three, was CPTED. USAID already had ample experience in the implementation and development of projects, based on this methodology, in México. In 2015, through USAID's 'Program for Citizen Living' (a precursor to the one hosting this project), had already produced a guide titled 'Safe Public Spaces Design Guide', which became an initial start-up methodologic reference for the project [9].

CPTED is a well-established and proven method for crime and violence prevention [10]. It is focused on spatial aspects in its first generation [11] and adds social ecology in its second generation [12].

"CPTED is a compendium of crime prevention strategies seeking to reduce the possibilities of crime of opportunity, as well as reducing fear in the community, augmenting its cohesion." [13] Its main hypothesis is that human behavior is influenced by physical and spatial conditions [14], where a sense of community is key for safe public spaces [15], and that the defense of public space depends on the capacity of the community to unite for a common good [16].

CPTED is originally based on a set of spatial criteria shaping the physical urban/architectural environment. However, as it emerged and was developed initially in Canada and the United States, it was crafted according to the physical characteristics of urban centers and neighborhoods of these countries. These are different to the spatial characteristics of Latin American urbanism and architecture. Northern México is no exception.

In Latin America, Macarena Rau, a Chilean author and CPTED expert, has spearheaded efforts in many countries of the region. Rau and the International CPTED Association (ICA) have tailored the methodology to better fit and respond to the social and spatial characteristics of Latin America. However, impact evaluation methods of CPTED in Latin America are still under development [17].

CPTED is generally organized around five basic principles and criteria:

1. Natural surveillance: The ability to see and be seen.

2. Territorial Strengthening: Public space identity and ownership.

3. Natural access control: A set of spatial design techniques to avoid exclusionary and aggressive urban/architectural elements.

4. Maintenance: Techniques to keep public spaces well maintained and cared.

5. Community Participation: The citizen as the expert participating in the construction and maintenance of his or her neighborhood. This aspect is not as present in the original, spatially oriented, first generation version of CPTED. 
These five principles were selected and planned to be sufficiently adaptable to specific constraints identified by implementation teams, local governments, NGOs, and local community members. For the purposes of this hybrid project, the fifth principle, largely based on Latin American experiences, was the fundamental articulation between spatial and social operations.

\subsection{Attention to Youth at Risk (AYAR)}

Young men between 15 and 25 years of age are the most vulnerable and likely to become victims or perpetrators of violence through recruitment into criminal organizations [18]. Many young men in these communities left school early, often with only partial or complete elementary education, and lack qualifications for employment. In México, this group is dismissively known as "Ni-ni", loosely translating as a person that neither studies nor works.

As a project with ample holistic social objectives, the inclusion of AYAR was crucial to mitigating current and future rates of crime and violence. AYAR expertise was sought and provided by a combination of technical support with experts hired by the international agency, local governments and their specialized entities, and non-governmental organizations, specialized in the subject matter.

AYAR was introduced conceptually to the technical team by YouthBuild, an NGO specialized in these activities with significant presence in Latin America. The process to implement an AYAR project is deployed in six phases [19]:

1. Community engagement: To identify young community members at risk and understand the community itself.

2. Recruitment: Identified youths at risk.

3. Training: Employment and education.

4. Insertion: Into their communities as functional members.

5. Follow-up: To monitor their progress in society, work and school.

6. Graduate mobilization: To have former recruits help in helping others.

YouthBuild introduced the Community Asset Building (CAB) method as part of the proposed initial plan. Other planned AYAR tools were both, group-oriented activities designed to unify young communities and mitigate conflict, and individualized tools, including the Youth Targeting Tool (YTT), which is designed to identify persons in high risk of becoming part of crime and violence. Group activities included music competitions, such as hip-hop tournaments and sport competitions. The individualized tool was implemented by experts who identified subjects who would become part of a program designed to convert individuals into functional members of society and prepare them for employment.

\subsection{Prevention of Gender Based Violence (PGBV)}

This component of the hybrid methodology was delivered in its technical capacity by experts who were part of the team by the international development agency, along with the premise that in the Mexican context 'we know that we do not know much about GBV' [20]. There is a lack of information around this type of violence as most of it goes unreported to the police, there is a lack of updated information, and there is little disaggregated data at local or municipal levels.

For the specific purposes of this study, the objective population were women subject to violence. A series of social activities, designed to raise the awareness of this problem, were brought in the process of implementation. Specifically, actions intended to de-normalize violence between romantic partners. With regards to spatial interventions, a conceptual foundation was the understanding that space is gendered [21]. This approach was employed to understand and signify the importance of sound urban and landscape design techniques to make safer public spaces for vulnerable populations. 


\section{The Selected Neighborhoods}

Chihuahua City is within the municipality of Chihuahua. The urban area of Chihuahua, of around 20,120 hectares, lies within the municipal boundary. The urban population of Chihuahua is 918,339 inhabitants [22]. Chihuahua, and in general, northern México, enjoys a relatively low grade of marginality and a high level of prosperity due to the industrialization of the border region with the United States.

Guadalupe is an urban municipality, which is almost completely urbanized, within the metropolitan area of Monterrey in the state of Nuevo León. The urban area of Guadalupe is 8,740 hectares with a population of 682,880 inhabitants. This urban area represents only the $11.1 \%$ of the total urban area of the metropolitan complex [23].

In México, municipalities are governed by a mayor who is elected every three years. It was just until the 2018 election cycle that mayors, nationwide, had the chance to seek reelection for a second term only. Mayors work within a top-down armature, where they can select all municipal officers, including the police chief. There are several decentralized entities that still depend on municipal taxes, including the Municipal Planning Institutes who assess and develop urban planning and policy for their human settlements.

The mayors in both Chihuahua and Guadalupe were eligible for their only additional and second three-year cycle, if they won reelection in the summer of 2018. The mayor of Chihuahua decided to run for re-election and won; the mayor of Guadalupe decided not to run for re-election. These circumstances may have been decisive in the development and implementation of the projects, as it is a socially oriented initiative with a potential result in political-electoral capital.

Both the Chihuahua and Guadalupe neighborhoods are composed of various phased and independent subdivisions, as opposed to one developed at the same time. These are also rather large, and because of their scale and physical urban design, difficulties arise in fostering cohesion in one social group or community. The people occupying these subdivisions arrived in phases, inhabiting successive phases of urbanization, further complicating social fragmentation.

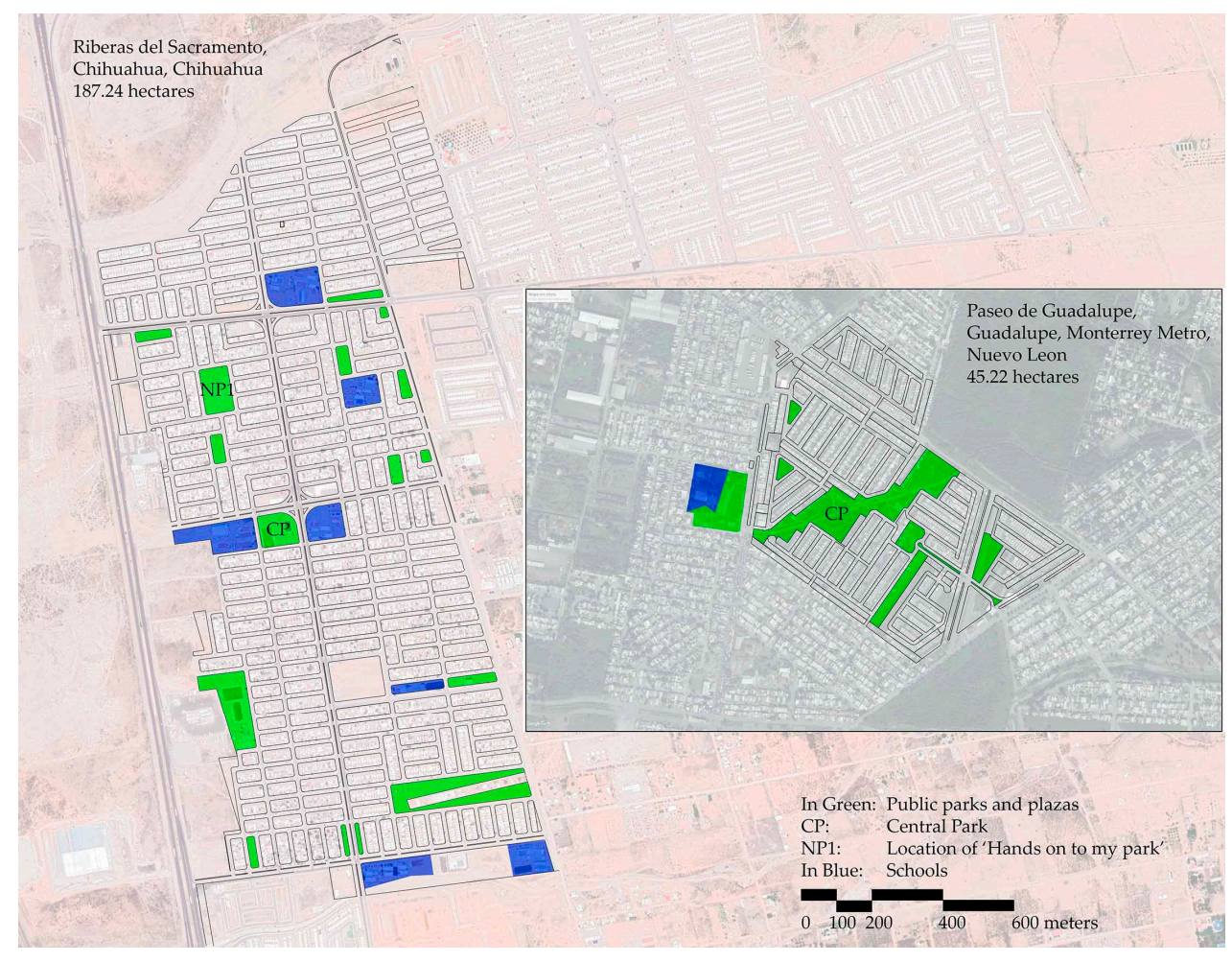

Figure 1. The Chihuahua Neighborhood (left) and the Guadalupe Neighborhood (right). Source: Author, with Google Earth Aerials and municipal cartography. 


\subsection{Riberas de Sacramento, Chihuahua City, Chihuahua}

The neighborhood is a 187.24 hectares polygon isolated from the continuous urban fabric at the north end of the western valley of the city of Chihuahua. According to INEGI's last census (2015), it has 5844 housing units, from which 1513 are abandoned, representing $25.9 \%$ of the total. The total population of the polygon was 13,114 people, for an average occupation of 3 persons per household. 4970 people were of ages 0 to 15 , representing $37.9 \%$, while 3,990 were of ages 15 to 29 , representing $30.4 \%$. Counting both together, this is a very young community, where $68.3 \%$ of its members were aged 29 or younger.

This neighborhood is a planned community with a dozen neighborhood scale parks and plazas. It also has a central square and park of 0.9 hectares. Around it are public middle, elementary, and kindergarten schools. Its urban design is defined by repetitive, long, rectangular blocks, a common and efficient geometry for achieving density and efficiency in infrastructure systems.

\subsection{Paseo Guadalupe, Municipality of Guadalupe, Monterrey Metropolitan Area, Nuevo León}

This is a neighborhood composed of various phased low- to middle-low income subdivisions. The 45.22 hectares polygon has 2160 housing units, with a total of 7560 inhabitants. A total of $26 \%$ of the population was between 0 and 15 years of age, $27 \%$ was between 15 and 29, while $29 \% 30$ to 49 , and $18 \% 50$ or more years of age.

The neighborhood includes 5.4 hectares of green areas-as parks and plazas are typically referred to in Mexican urban planning-which equal $12.6 \%$ of the total polygon area. In this sense, this community enjoys a significant share of dedicated public spaces, when compared to similar subsidized housing areas.

Of note is a central park, that runs along a transversal storm-water management canal. This park has an area representing about half of the open public space area of the neighborhood. It divides a northern half of the polygon with low-income housing from a southern half with middle-low income housing.

\section{Implementation Process}

\subsection{General Aspects of the Implementation Process}

Once agreements for collaboration were signed between USAID and the local municipal government, this hybrid project was implemented following these six phases:

\subsubsection{Diagnostics}

The general objective of this phase was to identify what, where, and when real and perceived threats to personal and communitarian safety. It was critical to understand the location and concentrations of perceived insecurity and therefore be able to intersect this with statistical data from the local police departments, municipal governments, and INEGI.

The social diagnostic tools employed included:

- Community walks: Executed at various times and days of the week to identify unsafe and safe areas within the neighborhood.

- Drawing workshops with elementary school children: Where children expressed their desires for their community, while also sharing where they felt safe and unsafe in their community.

- Community mapping workshops in open public spaces in the community: Where community members of all ages participated sharing their perceptions and opinions.

In addition to these community participation tools, a base-line study was collected by a specialized consulting firm for each neighborhood. This was in the form of a representative survey, which would collect opinions on the perception of public safety and the environmental state of the community. 
The results of these exercises were compiled and synthesized by the local consulting teams in each city, and then the results presented to municipal authorities and the community.

Assessments of the existing physical conditions of public spaces in both neighborhoods were executed during site visits by the technical team during the summer of 2017. In both neighborhoods, public spaces-in the form of small to medium neighborhood parks and plazas of an average area of 2500 to 5000 sq. $\mathrm{mt}$.- -were in generalized condition of deterioration and public lighting was damaged. Urban elements, such as benches and playgrounds, were in fair condition in most cases. One of the obvious problems in both neighborhoods was the lack of shade provided either, by trees or structures. Negative graffiti was ubiquitous. However, most importantly, the spaces were not being sufficiently used by community members. Most remained empty during the day, and only improved slightly once the higher temperatures receded.

This general assessment, done through a visual inspection by the technical team and municipal authorities, was confirmed by the social diagnostic results of both communities, where most neighbors pointed at desired parks and plazas with cared-for trees, vegetation, and shade.

\subsubsection{Planning and Design}

The plan for each project was guided by the technical team in collaboration with local municipal authorities, synthesizing the results of the diagnostic phase into a social and environmental set of operations.

However, the specific plan also responded to the level of operational capacity installed for each municipality. While, the Chihuahua plan was supported by a multi-sectorial working group, composed of diverse municipal entities and NGOs, the Guadalupe plan was tailored to fit a more executive format, that would cater to the local, socially-oriented, large employer companies as partners of the municipal government.

\subsubsection{Implementation}

The first step, which also preceded the formal implementation phase, was a capacitation effort for the training of public officials. In order to be able to implement novel methodologies and techniques in both cities, the project included a component for the development of local technical capacity in the various municipal government entities participating. A prime objective of the workshops was to train public officials on a new mode of communication with the people. As opposed to doing all the identification and programming of public works and operations themselves, the newly trained officials were tasked with establishing an effective communication channel with the communities they serve, in order to identify and respond to social and infrastructural needs. A series of training workshops for public servants was executed in both cities during the early months of diagnostics, design, and planning, and even through implementation.

The workshops included presentations from experts on the three areas of hybridization for the project. After these, quick workshop exercises on community participation and communication efforts were practiced amongst the workshop attendees. The government entities most critical for this were the departments of parks and recreation, public works, public safety (police), attention to youth and to women (which are today common in municipal governments of medium to large cities in México.) These workshops laid the foundation for the implementation of the various phases and components of both plans.

Recruitment and formation of neighborhood groups:

A fundamental part of the groundwork to enable implementation was the recruitment and formation of leadership individuals and groups in each of the neighborhoods. This was implemented by collaborative groundwork between the local technical team and the municipal government. 
Recruitment of local schools of architecture as project partners:

One of the strategies included in the project was the recruitment of the local schools of architecture, existing on each of the cities, to participate in the planning, design, and construction of public space recovery projects. This collaboration would also lead to the training of local schools of architecture in community participation techniques, where faculty and students would learn and practice how to design with, and for the community, while also increasing the social awareness and impact of the institutions and future professionals.

\subsubsection{Monitoring and Evaluation}

The project's initial framework required the development of tools to monitor the implementation and results of one of the project's components. These tools were developed by the technical team and were specifically crafted for each of the activities, wither in social or environmental interventions. These were also meant to be employed by each one of the implementation entities to self-monitor and report results to coordinating multi-sector groups.

\subsubsection{Systematization}

A phase where all initial phases were recorded and critically analyzed by the technical support team in order to effectively adjust to increase the feasibility of replication through the institutionalization of the project.

\subsubsection{Institutionalization}

A critical intention of this pilot project was to leave an installed local technical capacity for the replication of the project in other neighborhoods, that need to mitigate their crime rates and recover public space. This included the training of public servants and of academic institutions particularly schools of architecture, their faculty and students in the project methodology.

\subsection{Project Conceptualization and Branding}

A pre-requisite for the implementation of the project was its branding. The project was discussed and agreed with municipal authorities as a program with the objective to reduce crime and violence in troubled neighborhoods and districts of the cities. However, it was decided, as is common practice, to brand the initiative without explicit language in this respect. The projects were described and communicated as community building and physical reconstruction efforts. A project where the municipal government, with specialized technical support, would help communities organize and reclaim their public spaces.

The Chihuahua project was branded as "Mi colonia es mi casa en Riberas" or 'My neighborhood is my house in Riberas'. The Guadalupe project was branded as "Un paseo para todos" or 'a promenade for all'. Both included graphic imagery developed by the municipal government. Both proposals were presented to community members of each neighborhood early in the process to confirm acceptance and legibility of the community building message.

\subsection{Specific Aspects of the Implementation Process in the Chihuahua Neighborhood}

\subsubsection{Diagnostic Phase}

This phase was implemented from late 2016 to early 2017. The initial physical condition assessment identified in all public spaces dry and irrigation-less areas, which were supposed to be vegetated.

\subsubsection{Planning and Design Phase}

This phase was executed in March 2017. After synthesizing the results of the various activities, belonging to the participative diagnosis implemented in the neighborhood, the plan was encompassed in three general phases: 
1. Social mobilization: Where participatory processes for diagnostic and identification of social leadership in the community was executed.

2. Formation: Where neighborhood groups were organized and operationalized with the help of local citizen leadership and stakeholders.

3. Environmental improvement: Once a social organization was set in place, several plan components geared to the mitigation of crime and violence and the recovery of public space was implemented.

These phases organized the appearance of plan components, including: Repair and improvement of urban signage, maintenance and improvement of green areas in public spaces of the community, a campaign to improve and produce a safe culture of mobility (against reckless driving in particular), neighborhood clean-up campaign, citizen surveillance, addiction prevention activities, an integral program of activities (most of which happened in public spaces) for the local youth, a campaign against public scandal to promote a culture of respect between neighbors (bring down the noise of nightly parties), abandoned housing recovery, the establishment of a cultural corridor in the neighborhood, formation against violence, safe routes (with working public lighting and appropriate signage) to, and from, public transportation, and a flagship project in the transformation of the central public park into a much more functional and enjoyable public space.

This diversity of actions required an equal diversity of actors, stakeholders, and agencies. Including various municipal government entities, NGOs, schools and universities, and neighborhood groups. These were organized in realms belonging to each of the three areas (CPTED, AYAR, and PGBV), and the general coordination. This complex armature created a project ecosystem. (See Figure 2).

The plan was presented to a municipal board or multi-sectorial group, purposefully organized to evaluate, monitor, and implement the project, with representatives from various local government agencies, including the police, public works, planning institute, and others. This board was organized to meet periodically, on a monthly basis, to review the progress of the project's implementation. Eventually, not all initial components of the plan were implemented, and the plan itself was significantly transformed as project components and their interventions were made available for implementation, as determined by human, economic, and political resources.
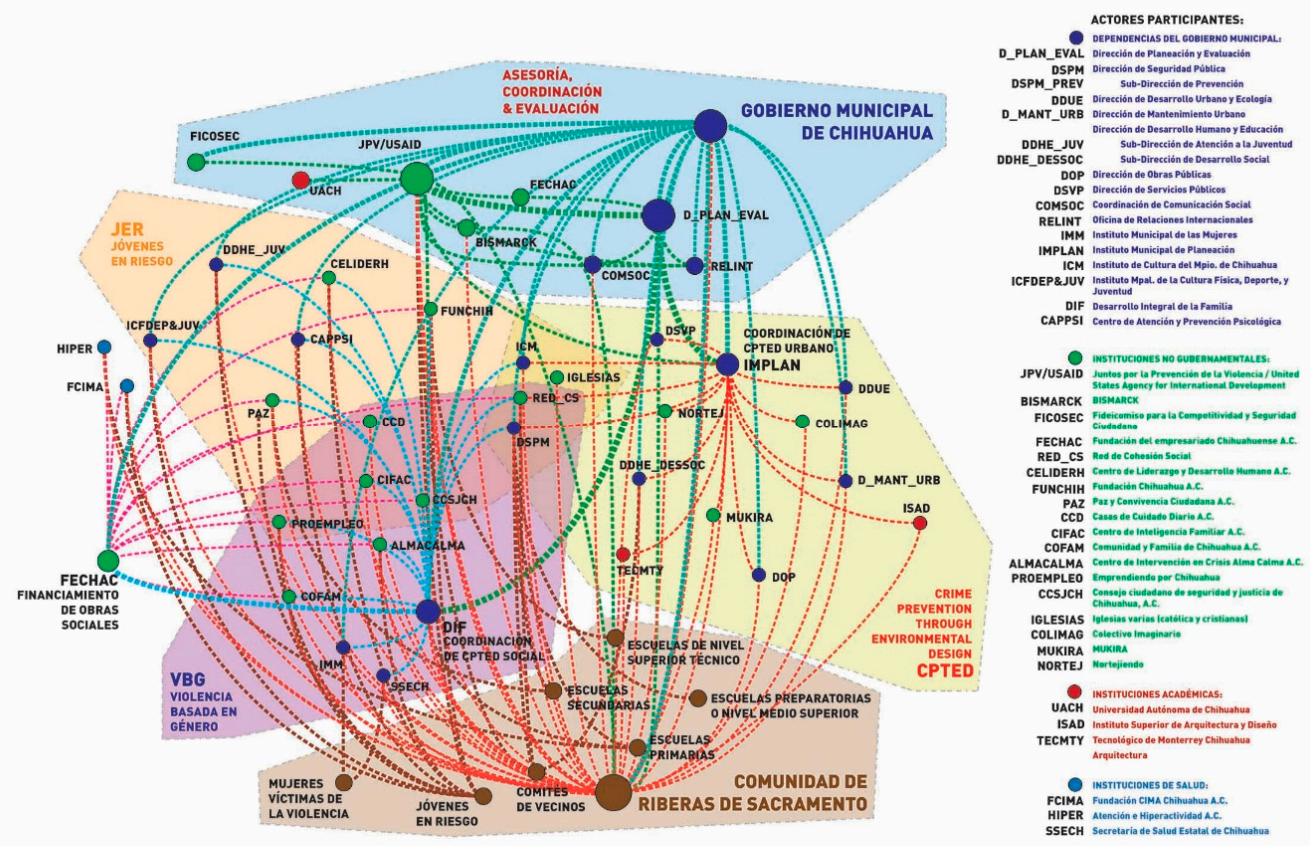

Figure 2. Ecosystem map of actors and areas of intervention for the Chihuahua neighborhood, in Spanish. Source: Author. 


\subsubsection{Implementation Phase}

The formation of neighborhood groups was implemented by the local consultant who identified, organized, and trained neighbors in a new model of communication with the local government, and in empowering them to participate in the maintenance and reshaping of their public spaces. The tools employed to organize these groups ranged from smart-phone applications such as WhatsApp, the local consultant put together a group consisting of hundreds of contacts to traditional posters and banners. This wide spectrum of communication tools was used to communicate training workshops and community meetings. Word-of-mouth was also instrumental.

The social and interpersonal skills of the local consultants and staff were determinant to successfully organize and establish groups of neighbors. While, full spatial coverage, in all the polygon, was not achieved, localized concentrations of working neighborhood groups were to prove critical for the later implementation of project components in the community. The local consultant had, in this case, the 'mystic' [24] to make this communication happen.

This neighborhood began positively in working with neighborhood groups and a collaborative municipal government actively engaging with the project.

On 9 June 2017, a one full-day kick-off implementation event was organized. It incorporated the participation of various municipal agencies and the presence of the mayor. The activities for this day included the clean-up, by municipal authorities, of the central park; the removal of rubble and trash from a vacant site identified by community members as a visual nuisance; collection and removal of large trash and discarded objects; fumigation of the public school yards (with direct participation of the mayor) and; the reopening of the local police station, which had been abandoned for years.

The local community was also actively involved on the first day. A mural painted by local youth, organized by the municipal art department, was completed. Middle-schoolers participated in the design and painting of a crosswalk connecting their school to the central park.

Significantly, at the reopening of the police station, local officials, including the chief of police and the mayor, gave speeches framing the efforts as part of the plan, and committing to working with the community to recover their public spaces.

Various activities were implemented over the remaining months of 2017 and early 2018. These were eventually executed without a strict following of the original plan, which was by itself conceptualized as a dynamic scheme. From these, one would stand out in the relationship to the public space recovery efforts.

\subsubsection{Hands on to My Park}

The "Manos a mi parque" or 'Hands on to My Park' project was executed during the second half of June and first half of July 2017 (Figure 3). This project component was led by the local Superior Institute of Architecture and Design, known as ISAD for its acronym in Spanish, who was recruited to participate in a public space recovery project. ISAD proposed to proceed within the framework of a quick and intensive summer studio for which they hired a Spanish professor, with a significant experience on this kind of projects, a local professor with expertise on public space design and landscape, and a local professor in carpentry and building.

Under the leadership of a member from Zuloark, the summer studio tackled the recovery of a neighborhood park, which was identified by community leadership as an important opportunity to strengthen their reclamation of public life. The park was in a typical condition of semi-abandonment. An arid, mostly devoid of shade park with a multi-purpose, basketball sized sports court, a playground, and gardened areas.

The studio departed from the diagnostic information collected and analyzed by the consulting team. The main complaints from the local community were identified and a studio was planned so that students would work with community members in the design and construction of the project. 
With the help of local leadership and the technical team, the studio group started the summer course with meetings, onsite, with community members, in order to extract a precise assessment of the issues and opportunities specific to the park. Within a timeframe of only five weeks, the studio was also tasked with searching for funding for materials required in the construction of the intervention.

The community process defined a project program largely consisting of three main needs in order to revitalize the park: Seating, shade, and gardening. In this program, the studio developed a series of design alternatives that were presented to the local community in a public meeting. A selection was done, and construction proceeded.

The building process took two weeks. Local children and teenagers participated onsite in painting and simple assembly, while students and professors coordinated the efforts and led the more technically challenging processes. The main design device was a steel-framed module, assembled at ISAD's workshop, which was then transported by truck to the park. Seating was designed into the module, and gardened planters were integrated into a $C$ shaped plan, fitted into one of the bare grounds but in central areas of the park.

A community event marked the completion of construction and opening to the public. This celebration included the participation of the municipal government and technical team.

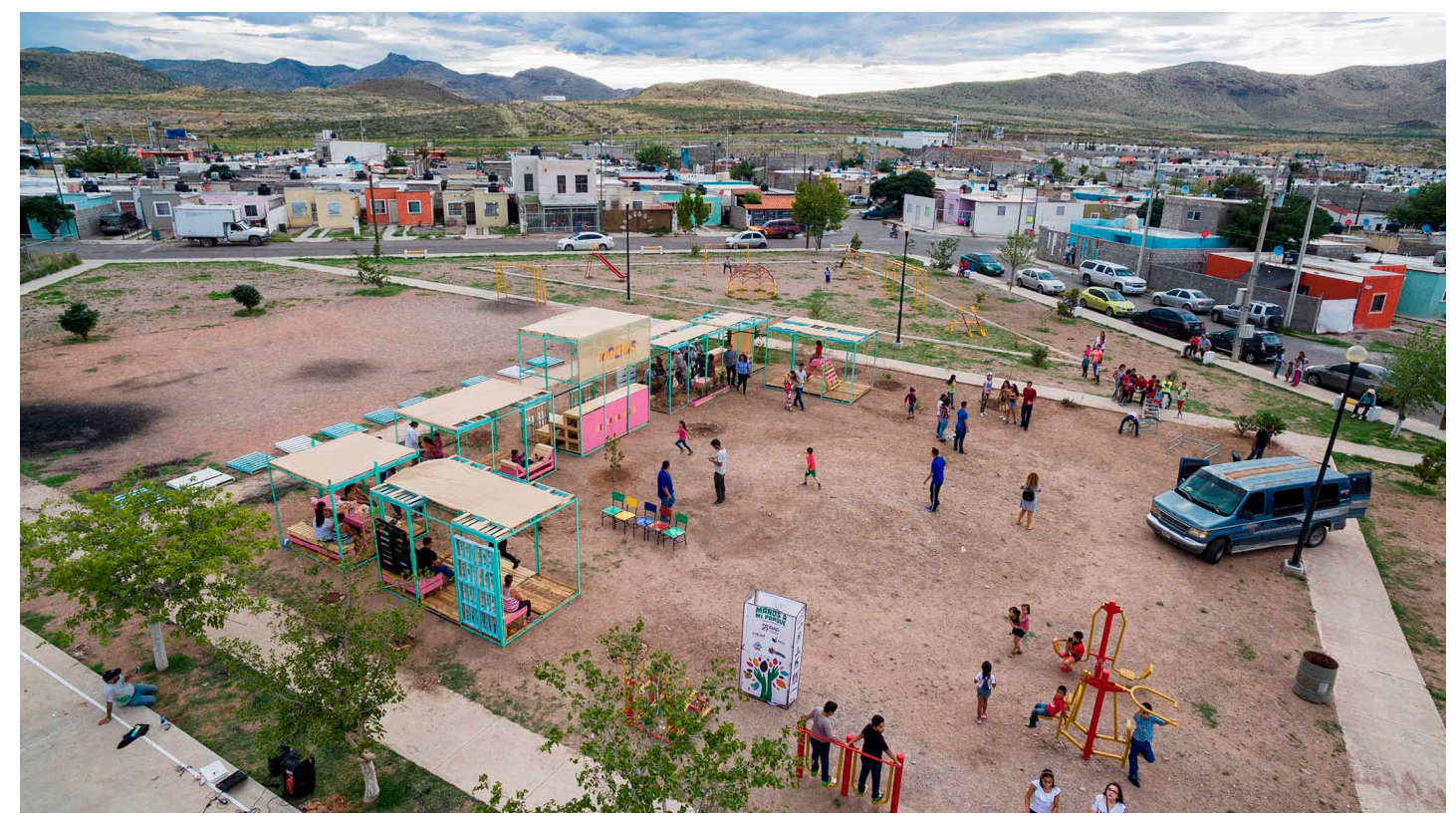

Figure 3. The 'Hands on to my park' project under construction, July 2017. Photograph: DELFOZ, Enrique Portillo.

Other efforts, led by the municipal government, were effectively implemented. This included a repair program of street signage, maintenance of public lighting, and reforestation of public parks in collaboration with community members. While, the signage and public lighting efforts posed obvious difficulties in allowing neighbors to join in the execution, these relied on community reporting for the identification of the most significant needs with respect to the orientation within the subdivisions and the perception of safety; citizens assisted in installing signage.

In comparison, the reforestation program was community-based. First, personnel from the parks and recreation department were provided with training for tree planting and care, through a series of community workshops held in streets and front yards of participating neighbors. The municipal government provided free trees, produced in the local municipal nursery, tools for excavation, and organic soil for fertilization. Several neighborhood parks were reforested in this collaboration. 
Additionally, up to eight different murals were painted between local youths and the technical and material support of the municipal government. The premise for the selection of themes was the need for positive messaging. These tactical urbanism activities were devised to integrate social and physical interventions, as well as allow for the construction of a critical mass to participate in social awareness actions.

With regards to social interventions, several activities were organized with the objective of activating public spaces in the polygon. These included hip-hop competitions, sports competitions, and music concerts. The AYAR component was implemented through the implementation of 36 surveys with the Youth Targeting Tool (YTT), designed to identify individuals at risk of becoming victims or perpetrators of violence. The PGBV component, included a series of workshops and theater shows, intended to de-normalize violence between romantic partners.

\subsection{Specific Aspects of the Implementation Process in the Guadalupe Neighborhood}

\subsubsection{Diagnostic Phase}

This phase was implemented from February to June 2017. In this neighborhood, the gardened areas were overgrown and unmaintained. The central park was identified as a hotspot for petty crime and violence. The park contains a central stormwater drainage canal, which is bridged by three structures that create chokepoints, that were often employed by criminals to ambush their victims. Because of this, few crossings occurred in these pedestrian bridges at night.

\subsubsection{Planning and Design Phase}

This phase started in June of 2017. An initial plan was crafted first, to cater to the main local employers within the municipality of Guadalupe. It was presented to the mayor, industrial, commerce, and service stakeholders in the early weeks of this phase. The plan was initially designed to deliver a series of projects, which could be distributed or adopted by various stakeholders in the community.

The plan was organized in three executive phases:

1. The first phase was composed of 'trust construction' projects. These included clean-up, maintenance and improvement of access points to the subdivisions and the central park. Access point interventions were focused on tactical urbanism techniques and defined by the urban design of the community, which included small commercial areas with convenience stores. The interventions included signage and urban art, intended to be financed and implemented by the companies owning the stores, in collaboration with young local community members. The central park clean-up and maintenance would be executed by organized neighbors in collaboration with the local government.

2. The second phase was characterized by the formation and improvement of spatial/environmental qualities. This included the retrofit of selected small parks and playground areas, access points, and traffic calming measures in a section of the community that identified unsafe pedestrian conditions as a priority. All these interventions were implemented in collaboration between the community and the municipal government.

3. The third and final phase was concentrated on the redesign and retrofit of the central park. The diagnostic phase identified the central park as a concentration of perceptions of insecurity. However, the socio-economic data also confirmed that the central park divided two communities of different incomes, thereby, transforming a social barrier into a physical barrier. All resources available to the community, including local government, neighbors, and participating NGOs contributed to this project. As the most expensive intervention in the plan, it was located at the end of the implementation process. More time would be allowed for financial resources to be garnered, while the accumulation of social and physical interventions of phases 1 and 2 would help solidify and build strong neighborhood groups to collaborate in a final project, bringing together the entire community. 


\subsubsection{Implementation Phase}

The preliminary work of the formation of neighborhood groups was not successfully executed in the Guadalupe neighborhood. The community had gone previous efforts in the formation of neighborhood groups and leaderships that failed. Lingering tensions between community leaders prevented the formation of groups.

Initially, the project received the support of the municipal government. On 1 June 2017, a 'macro-brigade' was implemented in the neighborhood. This was an event intended to bring the municipal government closer to the community. It involved the presence of executive entities related to the project areas, including public safety, public works, youth, and women. Even the mayor attended the event. Recreational and sports activities were deployed to attract people to the tables, which executed social diagnostic tools, such as additional community mapping exercises (see Figure 4). On 2 June 2017, a meeting with the main local employers and companies was held. The municipal government invited large, local employer companies to join and participate in the project.

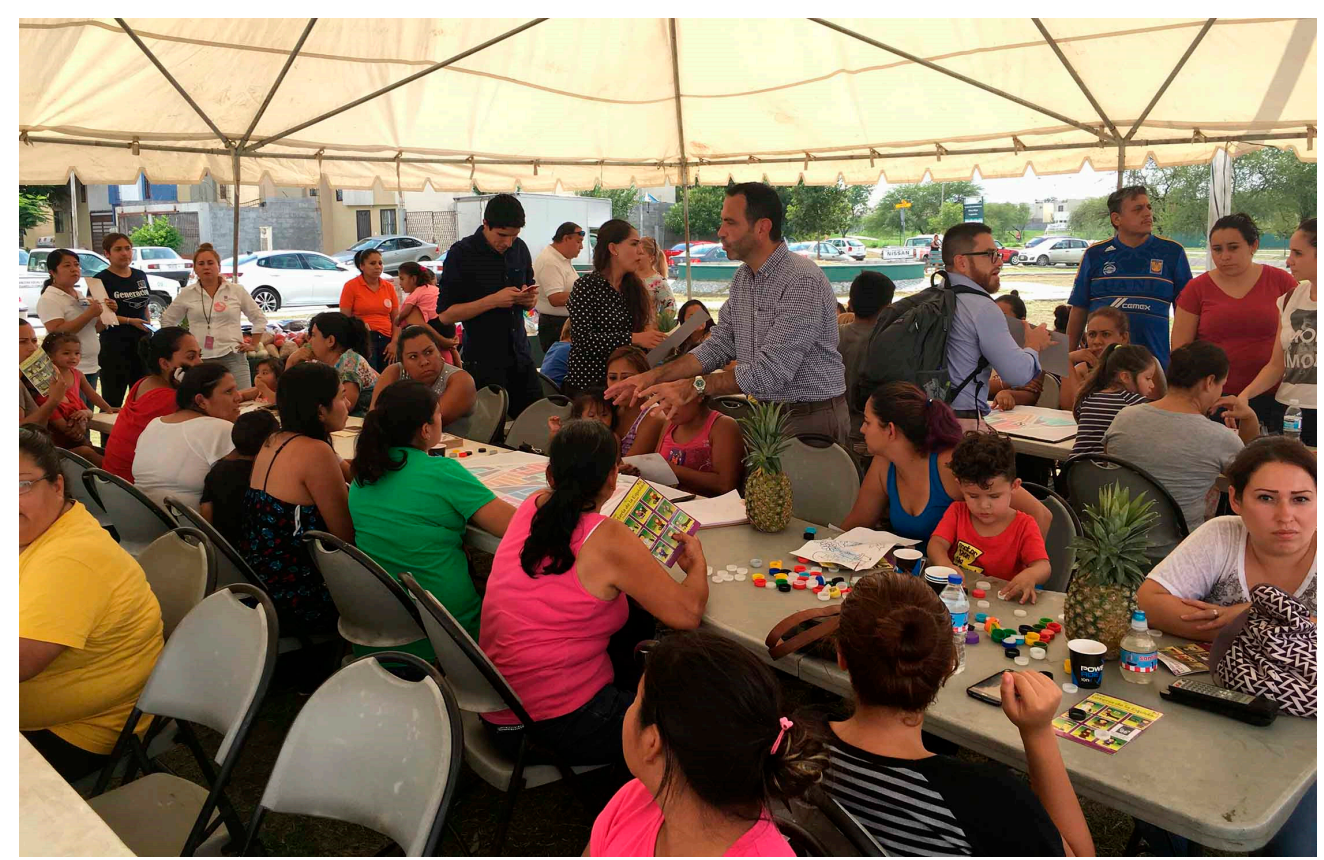

Figure 4. Community mapping exercise at the macro-brigade event in Paseo Guadalupe, Guadalupe, Nuevo León, México. Source: Author.

The physical/spatial interventions included the organization of one event at a local school for creative engagement of the young in painting crosswalk signage, a common tactical urbanism technique. A total of four neighborhood parks received maintenance, including clean-up, gardening, the repair of urban elements and public lighting, among others, with the support of OXXO, México's biggest convenience store chain and the participation of neighbors; and the implementation of three public service brigades, which consisted of coordinated visits from various municipal agencies to the neighborhood for general clean-up, weeding and gardening, repair of public lighting, and collection of citizen demands.

The social interventions were limited and only a fraction of those were included in the original pilot project framework. These included workshops with children from local schools to raise awareness on violence and crime, workshops on community centers for the same purpose, and a mobile classroom where job-skills training for women-intended to empower them-was delivered. The AYAR component remained largely unimplemented, as the application of the YTT was not executed. In the summer of 2018, SUPERA, an NGO, was planned to engage on a one-year intervention to address the issues in AYAR. 


\section{Results}

\subsection{Specific Results to the Neighborhood Interventions}

\subsubsection{Chihuahua Neighborhood}

The most significant evidence on the performance of the project, in the mitigation of crime and violence, was delivered by statistical records of the municipal police. The crime incidence report for Riberas de Sacramento for the period of January to June 2018, which coincided with the program's implementation in its various phases and components, demonstrated a clear decrease on reported crimes. Crimes decreased from 32 in June 2017, around the same time of the implementation of the 'trust construction projects', to 12 in the following year. However, the administrative faults -misdemeanors- reportedly rose from 48 in May 2017 to 107 in May 2018 [25]. The technical support team points to the possibility of increased calls to report these conducts, due to an increase in trust in the municipal government's police response and enhanced channels of communication between the community and the local government. This is, by itself, a potential success of the project.

It is unclear, unfortunately, how directly these results on crime rate mitigation relate to the community-oriented and public space recovery efforts, or to a more obvious presence of municipal government agencies and the local police. The latter increased its visibility in the polygon with the operational station and more frequent policing.

Mixed results would be revealed in other project components, specifically all those related to physical improvements of public spaces. The physical improvement of the public realm proved to be challenging. The 'Hands on to My Park' project was quickly vandalized and destroyed. While, there is no clear reason as to why this happened, it may be that this act of vandalism was a response from the local gangs against the organization of the community and the resulting physical manifestations. In other words, criminal groups and minds are not in favor of a stronger sense of union. Community guardianships [26], designed to protect collaborative neighborhood work, may have not been achieved, or the fear of local gangs was simply not erased.

However, the project methodology was successfully extended, fulfilling the institutionalization phase objective, to four other problematic neighborhoods, which were also developed in the first 12 years of the 21st century in the city of Chihuahua (see Figure 5). This was decided after one year of work in Riberas de Sacramento, and, in view of the success of the multi-sectorial municipal working group who had actively committed to the project. In this case, the technical support provided by the international development agency was substituted on the ground by the selection and training of 'neighborhood managers'. These were public municipal officials from different areas, but who shared an expertise in community organization and participation initiatives. The extension of the project's methodology to other neighborhoods is probably the most important product of this pilot project.

The preliminary results presented in the intermediate evaluation to the program 'My neighborhood is my house', demonstrated a clear improvement in various areas by measuring a six-month period from baseline to survey in the five neighborhoods where it was implemented. The victimization rate of persons who have themselves or a family member been a victim of crime fell from an average of $26 \%$ to $8 \%$. The general perception of insecurity in the neighborhoods fell from $64 \%$ to $39 \%$. However, only $29 \%$ of the community members of these neighborhoods were aware of physical improvements, that were implemented as part of the program in their public spaces [27].

\subsubsection{Paseo Guadalupe}

In the March 2017 to August 2018 period, when the technical support team consultants were present, the partial implementation of the project in this neighborhood did not result in measured results, including in the improvement of public space, other than the activities briefly described in the implementation section. It did, however, provide valuable lessons to be discussed in the next section. 


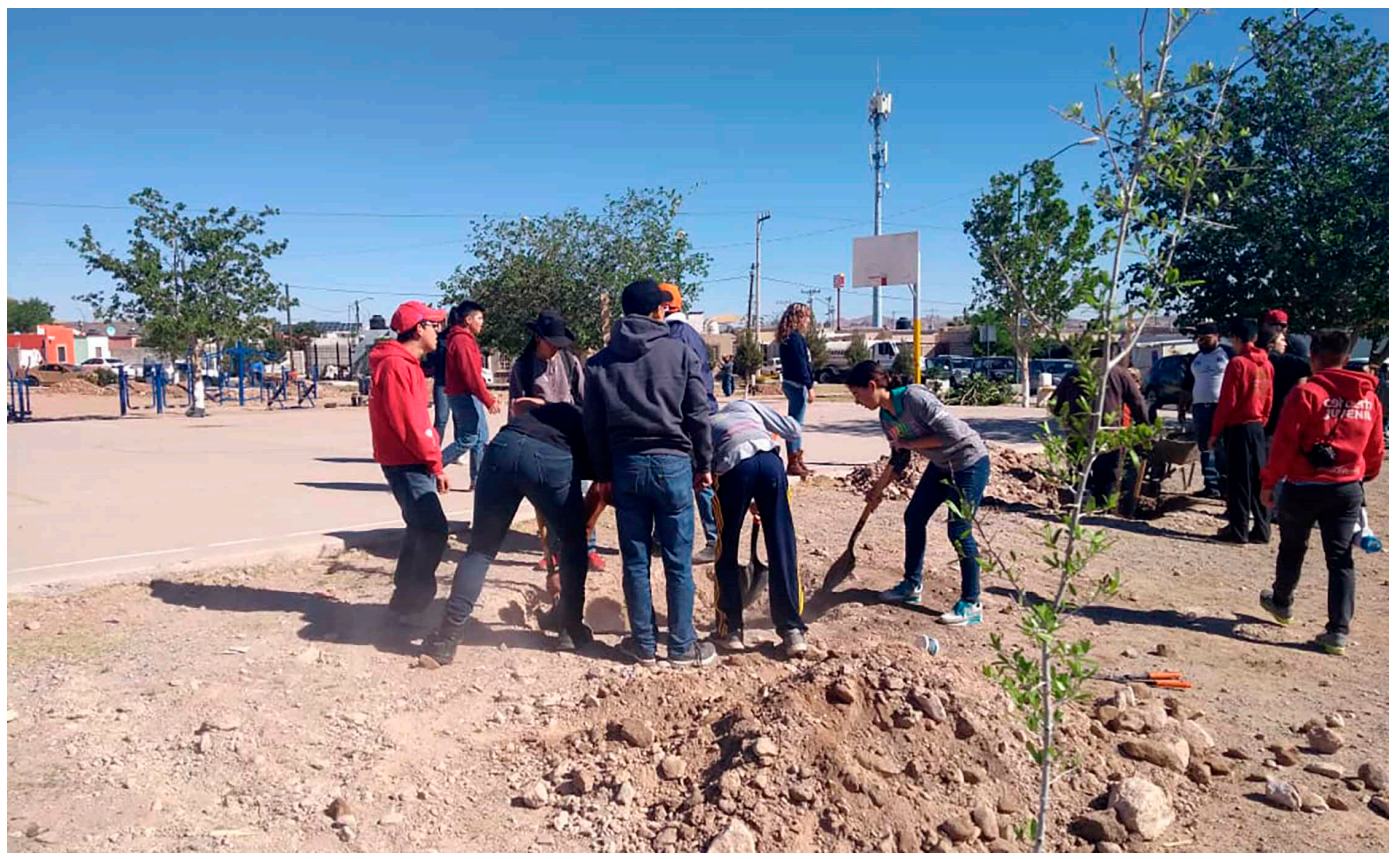

Figure 5. Reforestation in a joint collaborative effort between the municipal government and teenagers from a neighborhood under the extension project in Chihuahua City. Source: Marta Raquel Facio.

\subsubsection{General Results to the Hybrid Methodology}

As intended, since the beginning of this consultancy project, a systematization document was produced and delivered to both the international development agency and the participating municipal governments of Chihuahua and Guadalupe.

At the planning and strategic level, the local planning institute of Chihuahua (IMPLAN), who actively participated in several interventions and studies supporting the project, tasked itself with including the hybrid methodology and its concepts into the future update of the urban plan of the city. IMPLAN worked with aspects related to community engagement and participation, social and spatial crime prevention, and a policy to integrate and propitiate neighborliness, in what are often fragmented housing subdivisions and even traditional 'barrios'. This would be in fulfillment of the institutionalization objective of the project.

\section{Discussion}

The project's process of implementation produced and confirmed a series of critical questions in relation to the pertinence and feasibility of this kind of project and its concepts in the urban and social Mexican context.

On 10 August 2019, an important local newspaper, the Diario de Chihuahua (Chihuahua Daily, in Spanish), published an editorial note on the Riberas de Sacramento neighborhood as being marked by violence. Murder and violence have continued to be prevalent in the community [28]. Organized criminal activities and high-impact executions have continued to occur regularly. This may be a reminder of the limitations of crime and violence prevention strategies that focus on situational or opportunistic crime and violence. This hybrid methodology does not impact targeted crime and violence and may be therefore of limited use.

With respect to the hybridization of the methods, reconciling and coordinating processes with the various demands on time was confirmed to be highly complex and difficult to achieve. Spatial/physical interventions to retrofit and rehabilitate the public space, ranged from the immediate and quickly accessible, such as tactical urbanism interventions, to the long-term and expensive, like the full retrofit of central parks. Effectively identifying, training, and graduating the local at-risk youth is 
time-consuming and requires sustained efforts. Raising awareness against gender-based violence to the extent where evidence can be collected to demonstrate results, requires even more time and its own processes. Analyzing the three trajectories of implementation, one beside the other, requires a highly responsive and adaptable system, and, even if willing, the local protocols and processes of various municipal entities and NGOs are often sluggish and rigid.

For the purposes of public space recovery, the larger questions lie with the central method in achieving the prevention of crime and improving the perception of safety.

First, the spatial aspects of CPTED conflict with critical ecological needs of natural systems belonging to open public and private spaces of cities. What is the method for achieving open visual fields, while allowing riparian habitats to be restored? Especially, when it is precisely in creeks and rivers where some shade can be achieved with the right techniques, and species are present to produce cooling effects and micro-climate conditions that may propitiate more active public spaces. How can you implement the introduction of native plants, beyond the conventional groundcovers, such as the English-origin lawn, while maintaining visual control of public spaces? These questions are particularly relevant in the context of arid-Chihuahua, with $403 \mathrm{~mm}$ of annual precipitation and the semi-arid, Monterrey Metro, with $604 \mathrm{~mm}$ [29]. Moreover, the location of Riberas de Sacramento, in Chihuahua, is over an over-exploited aquifer [30] in dire need of measures to capture and infiltrate stormwater for the replenishment of underground water sources.

Second, many of the spatial/physical techniques and design criteria from CPTED originate in the urban and suburban form of a neighborhood morphologies of Canada and the United States. México's urban form is more compact and denser. The spatial thresholds that enable some of the design concepts, employed by CPTED, either are simply non-existent, or have to be reframed to more compact dimensions. While CPTED has updated its criteria to a 'second generation' applicable to Latin American urban form and society, more precise application is required, and guidelines, in the intensive occupation of space existing in México and Latin America.

The evolution and understanding of the relationship between space/environment and crime/violence is ongoing. While, CPTED was concentrated on the qualities of the environmental conditions, which would propitiate or discourage crimes of opportunity, in its first iteration, its second generation incorporated an emphasis on social and neighborhood ecology. A proposed third iteration of the methodology may be more effective in addressing questions of sustainability and public health [31], which are like those presented in this discussion.

The contemporary conditions of deterioration and abandonment of public space, in the ubiquitous, low-income subsidized communities of México, clearly require considerations to effectively improve the quality of life in these communities. INFONAVIT, the National Institute for Workers Housing of México, has in 2013, through 18 federal administrations attempted to tackle this issue by developing design concepts and criteria. Some of these were implemented in public parks and plazas of selected neighborhoods in México, mostly in México City, through the program "Mejorando la Unidad" Spanish for 'Improving the Unit', in reference to how mid-rise subsidized housing is commonly known. INFONAVIT's gamble is mostly based on high-quality architectural and landscape architectural design and community participation. One of the most well-known examples of the program is the San Pablo Xalpa Unit public space rehabilitation by Rozana Montiel Architecture Studio [32]. It may be a good exercise to compare this approach to the crime prevention approach, described in this article, and consider which model may lead to higher success.

This project poses more questions than answers as it intersects a socially oriented spatial design with an emphasis on preventing violence against vulnerable populations.

With regards to the violence inflicted on women, it is important to acknowledge the limitations, as $43.9 \%$, the most significant share of this kind of violence, occurs between romantic partners, Nonetheless, 'community' violence occurs in $38.7 \%$ of cases, of which $65.3 \%$ takes place in streets and other public spaces [2-8]. There may be an opportunity to improve this through gender sensitive public space design [33]. Architectural design might also be improved to mitigate conditions of overcrowding 
and comfort efficiency in small subsidized homes, potentially lessening domestic violence. It has been demonstrated, among others, through the analysis of the subject in Hermosillo, Sonora, in northern México, that there is a relationship between environmental conditions of housing and violence [34].

There may be a clearer effective path in the relationship between higher spatial quality of public spaces, and the ability of these to instigate higher activation and use from young populations.

As an example, in the Chihuahua neighborhood, the most successful public space infrastructure was a box gymnasium, built just a few years before the implementation of this project, but with a manifest interest on delivering high quality architecture in places where it does not normally happen [35]. Following a similar model to the recent approach to high quality public infrastructure in low-income neighborhoods made famous worldwide as 'Social Urbanism' with a capacity to mitigate violence as is the case of Medellin [36] and Bogota, in Colombia. This gymnasium was both the most visible and active recreational and sports infrastructure in the neighborhood, and it may deserve additional analytical attention to replicate and improve the model locally.

Finally, one other complex barrier for the implementation of the project, was the definition of the neighborhood boundaries. Where is the neighborhood and its community of neighbors? Where are the geographic limits of a particular social group? Is there one community in a polygon with thousands of housing units and population? If not, how many? Establishing the limits to a social group includes isolating it from the dynamic mantle of the city and this can be an ineffective and arbitrary act [37].

The implementation of the project, in the case of Paseo Guadalupe, demonstrated that the area of action or study cannot be defined only by a criterion, established by subdivisions and their progressive accumulation. In this case, this decision proved to be inadequate, since the neighborhood's polygon was determined spatially by construction phases of different income strata. In a neighborhood divided by a central, supposedly unifying public space, with one half of low-income housing and the other with middle-low income housing, the result, at least for the purposes of public space, was the opposite: the enactment of spatial separation and segregation.

Therefore, in addition to employing statistical data on crime, violence, and social issues, there is a need for spatial analysis and urban systems criteria to determine the areas of implementation. This could be done if Municipal Planning Institutes actively collaborate with public safety and other municipal entities in the establishment of community, or neighborhood, boundaries. And these will still have to be confirmed with work on the ground, with community members.

\section{Conclusions}

Developing a Mexican and/or Latin American crime prevention model, through community participation with an emphasis on vulnerable populations, working in tandem with a sound urban landscape and architectural design, is still a pending task. The value of this pilot project and its attempt to hybridize three well-known approaches in social ecology, as well as urban and landscape architectural design, resides in the testing of the feasibility of implementation of a multi-sector and multi-entity, complex initiative, based on process over time.

Some final reflections, shared by project team members, during project wrap-up meetings for Paseo Guadalupe, have shed light on some of the aspects described and discussed in this article. First, it may be that this project was too complex to be successfully implemented. The large number of topics, methods, tools, stakeholders, and actors with insufficient political capital proved a challenge for implementation. An unstable political leadership due to electoral timing and limited available economic capital resulting in few resources to be possibly directed for the improvement of public infrastructure, may point to an opportunity for future testing with less ambitious objectives and scale. More targeted and punctual interventions, which may be related to smaller and more precise neighborhood units, may be more achievable. The time span of implementation can also be shorter, this would allow for more precise and immediate commitments from both the community and the government [38]. 
The most significant reward is likely to be the will from both municipal governments and local communities to collaborate in projects of this nature. Especially important is the emerging empowerment of communities capable of enabling positive change. Municipal officers were willing to learn a new mode of communication and action with their constituents. Citizens and neighbors felt enabled to participate in the construction of their communities and reconstruction of their physical realm. It is just a matter of fine tuning to deliver, in a future iteration, a model that can be efficiently replicated by other communities in need of improving their quality of life and space.

Funding: This research received no external funding.

Conflicts of Interest: The author declares no conflict of interest.

\section{References}

1. Steffens, K. Urbanismo Táctico 3: Casos Latinoamericanos; Ciudad Emergente \& Street Plans: Miami, FL, USA, 2013.

2. Herzog, L. Global Suburbs: Urban Sprawl for the Rio Grande to Rio de Janeiro; Routledge: New York, NY, USA, 2015.

3. Sanchez-Corral, J. La Vivienda "Social" en México; JSa: México City, Mexico, 2012.

4. Diaz-Montemayor, G. A Northern Periphery: Issues of Landscape and Urbanism in Chihuahua; AULA: Houston, TX, USA, 2012.

5. Carpenter, T.G. The Fire Next Door: México's Drug Violence and the Danger to America; Cato Institute: Washington, DC, USA, 2012.

6. INFONAVIT (Instituto del Fondo Nacional para la Vivienda de los Trabajadores). Atlas del Abandono de Vivienda; INFONAVIT: México City, Mexico, 2015.

7. Heise, L.; Ellsberg, M.; Gottmoeller, M. A global overview of gender-based violence. Int. J. Gynecol. Obstet. 2002, 78, S5-S14. [CrossRef]

8. INEGI (Instituto Nacional de Estadística y Geografía). Encuesta Nacional Sobre la Dinámica de Loas Relaciones en Los Hogares (ENDIREH); INEGI: Aguascalientes, Mexico, 2017.

9. USAID (United States Agency for International Development); SEGOB (Secretaría de Gobernación). Guía para el diseño de espacios públicos seguros. In Programa Para la Convivencia Ciudadana; USAID: México City, Mexico, 2015.

10. Crowe, T. Crime Prevention Through Environmental Design, 1st ed.; Elsevier: Amsterdam, The Netherlands, 1991.

11. Saville, G.; Cleveland, G. Second Generation CPTED: Rise and Fall of Opportunity Theory. In 21st Century Securiy and CPTED: Designing for Critical Infrastructure Protection and Crime Prevention, 2nd ed.; CRC Press: Boca Raton, FL, USA, 2013.

12. Cozens, P.; Saville, G.; Hillier, D. Crime prevention through environmental design (CPTED): A review and modern bibliography. Prop. Manag. J. 2005, 23, 328-356. [CrossRef]

13. International CPTED Association (ICA). Available online: http://www.cpted.net/ (accessed on 1 August 2019).

14. Rau, M. Prevención del crimen mediante el diseño ambiental en latinoamérica. Un llamado de acción ambiental comunitaria. In Ciudad y Seguridad en América Latina; FLACSO: Santiago, Chile, 2005.

15. Jacobs, J. The Death and Life of Great American Cities; Vintage Books: New York, NY, USA, 1960.

16. Newman, O. Creating Defensible Space; U.S. Department of Housing and Urban Development: Washington, DC, USA, 1996.

17. Rau, M.; Cartes, I.; Gatica, F.; Pascoe, T. Impact Evaluation of Situational Prevention Strategies and CPTED (Crime Prevention through Environmental Design) in Vulnerable Neighborhoods in Latin America. J. Appl. Secur. Res. 2019, 13, 437-454. [CrossRef]

18. Vanderschueren, F. From Violence to Justice and Security in Cities. Environ. Urban. 1996, 8, 93-112. [CrossRef]

19. Qusba, N. Building Communities, Building Lives; YouthBuild: Somerville, MA, USA, 2017.

20. Pollock, J. Género, Violencia, y la Ciudad: Planeación Urbana con Perspectiva de Género; Fundación Idea: La Paz, Bolivia, 2017.

21. Massey, D. Space, Place, and Gender; University of Minnesota Press: Minneapolis, MN, USA, 1994.

22. UN-Habitat. City Prosperity Index, CPI, Chihuahua; UN-Habitat: Nairobi, Kenya; INFONAVIT: México City, Mexico, 2018. 
23. UN-Habitat. City Prosperity Index, CPI, Guadalupe; UN-Habitat: Nairobi, Kenya; INFONAVIT: México City, Mexico, 2018.

24. Wilson, P. The Heart of Community Engagement: Practitioner Stories from Around the Globe; Routledge: London, UK, 2019.

25. DSPM (Dirección de Seguridad Pública Municipal). Incidencia Delictiva: Riberas de Sacramento, Periodo Enero-Junio 2018; Report produced for the Municipal Government of Chihuahua; DSPM: Chihuahua, Mexico, 2018.

26. Reynald, D. Translating CPTED into Crime Preventive Action: A Critical Examination of CPTED as a Tool for Active Guardianship. Eur. J. Crim. Policy Res. 2010, 17, 69-81. [CrossRef]

27. FICOSEC (Fideicomiso para la Competitividad y Seguridad Ciudadana). Evaluación Intermedia al Programa mi Colonia es mi Casa; Report prepared for the multi-sectorial group of the Municipality of Chihuahua; FICOSEC: Chihuahua, Mexico, 2018.

28. De Chihuahua, E.D. Riberas del Sacramento marcada por la violencia. Available online: https://www. eldiariodechihuahua.mx/local/riberas-del-sacramento-marcada-por-la-violencia-20190810-1549394.html (accessed on 11 August 2019).

29. CLIMATE-DATA, Reports for Chihuahua and Monterrey, México. Available online: https://en.climate-data. org/ (accessed on 12 September 2019).

30. CONAGUA (Comisión Nacional del Agua). Actualización de la disponibilidad media anual de agua en el acuífero el Sauz-Encinillas (0807), Estado de Chihuahua. Diario Oficial de la Federación, 4 January 2018.

31. Mihinjac, M.; Saville, G. Third-Generation Crime Prevention Through Environmental Design (CPTED). J. Soc. Sci. 2019, 8, 182. [CrossRef]

32. Arch Daily México, Construyendo Común-idad/Rozana Montiel Estudio de Arquitectura. Published on 7 October 2015. Available online: https://www.archdaily.mx/mx/774927/construyendo-comun-unidadrozana-montiel-estudio-de-arquitectura?ad_source=search\&ad_medium=search_result_all\# (accessed on 6 August 2019).

33. URBACT. Gender Sensitive Public Space? Placemaking and Spatial Justice through the Perspective of Gender. European Union: European Regional Development Fund. Available online: https://urbact.eu/ gender-sensitive-public-space-placemaking-and-spatial-justice-through-perspective-gender (accessed on 12 September 2019).

34. Corral-Verdugo, V.; Barron, M.; Cuen, A.; Tapia-Fonllen, C. Housing habitability, stress and family violence. Psyecology 2011, 2, 3-14. [CrossRef]

35. ArchDaily México, Gimnasio de box en Riberas/Urbanika. Published on 13 March 2014. Available online: https:// www.archdaily.mx/mx/02-343861/gimnasio-de-box-municipal-en-riberas-del-sacramento-urbanika (accessed on 6 August 2019).

36. MacLean, K. Social Urbanism and the Politics of Violence; Palgrave Macmillan: Basingstoke, UK, 2015.

37. Foster, K.; Hipp, A. Defining Neighborhood Boundaries for Social Measurement: Advancing Social Work Research. Soc. Work Res. 2011, 35, 25-35. [CrossRef]

38. USAID Technical Support Contractor Team. Sistematización de la Intervención CPTED + Jóvenes en Riesgo + Perspectiva de Prevención de la Violencia Basada en Género: En la Colonia Riberas De Sacramento y Réplicas en otras Colonias de la Ciudad De Chihuahua, Chihuahua, y en la Colonia Paseo Guadalupe, Guadalupe, Nuevo León, México; Programa 'Juntos por la Prevención de la violencia'; USAID: México City, Mexico, 2018.

(C) 2019 by the author. Licensee MDPI, Basel, Switzerland. This article is an open access article distributed under the terms and conditions of the Creative Commons Attribution (CC BY) license (http://creativecommons.org/licenses/by/4.0/). 